\title{
Mechanisms of Protein Retention in the Golgi
}

\author{
David K. Banfield \\ Division of Life Science, The Hong Kong University of Science and Technology, Clear Water Bay, \\ Kowloon, Hong Kong, SAR of China \\ Correspondence: bodkb@ust.hk
}

The protein composition of the Golgi is intimately linked to its structure and function. As the Golgi serves as the major protein-sorting hub for the secretory pathway, it faces the unique challenge of maintaining its protein composition in the face of constant influx and efflux of transient cargo proteins. Much of our understanding of how proteins are retained in the Golgi has come from studies on glycosylation enzymes, largely because of the compartment-specific distributions these proteins display. From these and other studies of Golgi membrane proteins, we now understand that a variety of retention mechanisms are employed, the majority of which involve the dynamic process of iterative rounds of retrograde and anterograde transport. Such mechanisms rely on protein conformation and amino acid-based sorting signals as well as on properties of transmembrane domains and their relationship with the unique lipid composition of the Golgi.

$T^{\mathrm{h}}$ he functional integrity of an organelle is intrinsically linked to its protein and lipid composition. The protein and lipid composition of the organelles that make up the secretory pathway are established and maintained by recognizing and retaining proteins that function in a particular organelle whereas permitting nonresident proteins to move on to other destinations-either through anterograde or retrograde transport. In general, proteins and membranes are shuttled throughout the secretory pathway in membrane-bound carriers known as transport vesicles. Vesicle-mediated trafficking events are controlled by: the machinery that drives vesicle formation (the vesicle coat proteins and their GTPase effectors); vesicle docking/tethering factors; membrane proteins that mediate membrane fusion events (the SNAREs); and cells have evolved mechanisms by which to compartmentally localize these proteins. The affinity of a protein for a particular vesicle generating coat complex likely has a dramatic impact on the steady-state distribution of a protein (Heinrich and Rapoport 2005).

The Golgi serves as the major protein sorting hub for the secretory pathway, receiving de novo synthesized proteins from the endoplasmic reticulum (ER) that are destined for secretion from the cell, or for residence in the endocytic branches of the secretory pathway, or the plasma membrane. In addition, ER resident proteins that have overridden their ER retention mechanisms are captured in the Golgi and returned to the ER (Glick and Nakano 2009; Jackson 2009). The Golgi also receives,

Editors: Graham Warren and James Rothman

Additional Perspectives on The Golgi available at www.cshperspectives.org

Copyright (C) 2011 Cold Spring Harbor Laboratory Press; all rights reserved; doi: 10.1101/cshperspect.a005264

Cite this article as Cold Spring Harb Perspect Biol 2011;3:a005264 
D.K. Banfield

sorts, and retains the numerous integral membrane protein residents of its various subcompartments (cisterna) (Fig. 1). In the face of this constant influx and efflux of proteins, how then does the Golgi retain its resident proteins and hence its structural and functional integrity? The answer to this question is probably best understood for the integral membrane proteins that function in protein and lipid glycosylation-the glycosyltransferases and glycosidases (Colley 1997; Opat et al. 2001; Tu and Banfield 2010) although identification of retention signals in other protein residents of the Golgi have also contributed to our understanding (Machamer 1991; Gleeson 1998; Munro 1998; Saint-Jore-Dupas et al. 2004). In general, protein retention in the Golgi can perhaps best be viewed as a dynamic process in which one or more features of a Golgi resident protein contributes, to varying degrees, to its steady-state retention in a particular subcompartment. Nonetheless, when the "balance" of retention is perturbed, protein retention in the Golgi is affected.

The emerging picture is one in which the retention of proteins in the Golgi at steadystate is brought about through iterative cycles of anterograde and retrograde transport. The extent to which each transport pathway contributes to the retention of proteins within the Golgi is influenced by protein-protein interactions and the affinity of proteins for the lipid environment of Golgi membranes, as well as by the binding affinity of proteins for the COPI and COPII vesicle coat complexes (Harris and Waters 1996; Toderow et al. 2000; Sato et al. 2001; Abe et al. 2004; Saint-JoreDupas et al. 2004; Glick and Nakano 2009; Jackson 2009; Fig. 2). The physiological relevance of the dynamic nature of Golgi membrane protein retention is exemplified by the recent discovery that growth factor stimulation can induce the redistribution of certain glycosyltransferases from the Golgi to the ER (Gill et al. 2010).

In this article, I review what is currently understood about the mechanisms cells employ to retain proteins in the Golgi, with a particular emphasis on integral membrane proteins. Because of restrictions on the length of this review, protein retention mechanisms within the trans-Golgi network (TGN) will not be covered here. However, several excellent reviews covering this topic are available elsewhere

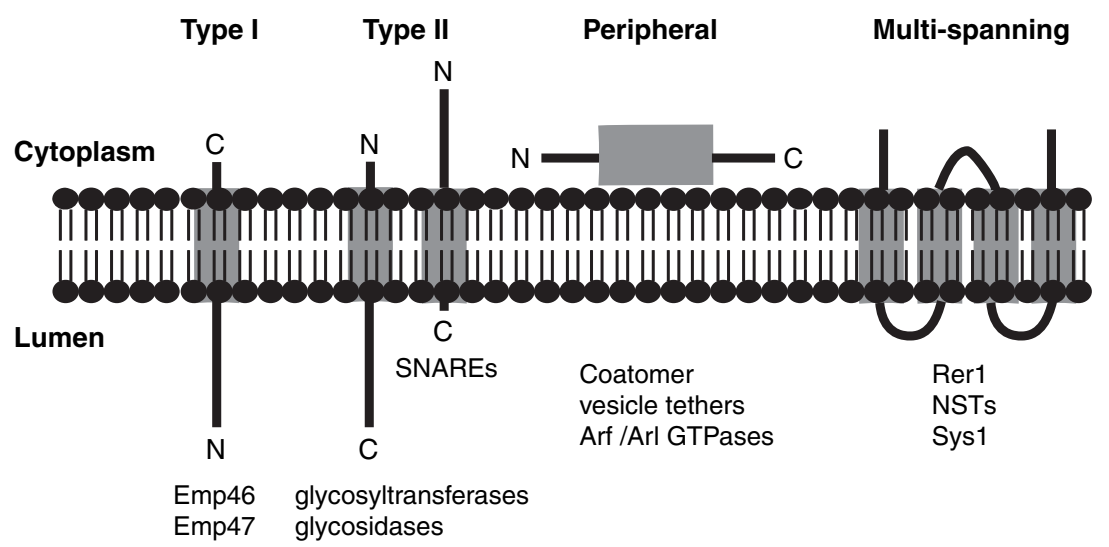

Figure 1. The membrane topology of Golgi resident proteins. The majority of Golgi integral membrane proteins are type II; of these the retention mechanisms employed by the glycosyltransferases/glycosidases and by the SNAREs, have been best characterized. Peripheral membrane proteins may associate with Golgi membranes through protein-protein interactions, protein-lipid interactions or because of posttranslational modification (not depicted) see text for details. Representative proteins, which are highlighted in this article, are listed below their corresponding topology. For simplicity, only one representation of a multispanning membrane protein has been shown. 

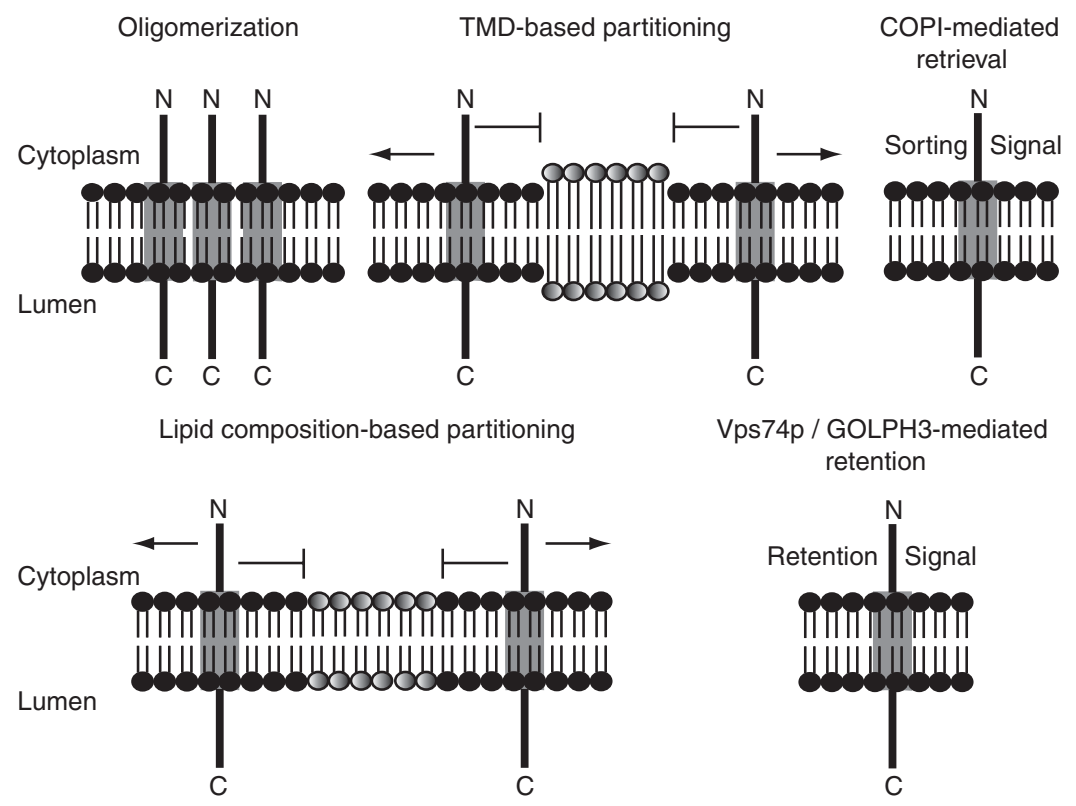

Figure 2. Models and mechanisms of integral membrane protein retention in the Golgi. For simplicity, only a type II membrane protein is depicted; however, such retention strategies may apply to proteins of different topology as well as to multimembrane spanning proteins. Sorting signals may be either conformational or amino acid sequence-based (see text for further details). TMD (transmembrane domain). Figure adapted from Tu et al. (2010) and reprinted with the permission from Springer@ 2010.

(Bonifacino and Rojas 2006; Glick and Nakano 2009; Pfeffer 2009).

\section{THE PARADIGM FOR GOLGI PROTEIN RETENTION}

In addition to its role as a protein-sorting hub, the Golgi also plays important roles in lipid biosynthesis and in the posttranslational modification of proteins and lipids by sugars. The enzymes that carry out these processes often localize to a particular Golgi subcompartment or cisterna and this is particularly so for enzymes involved in glycosylation - the glycosyltransferases. Glycosyltransferases are type II integral membrane proteins that display an evolutionarily-conserved modular organization. These enzymes are comprised of a short cytoplasmically orientated amino terminus (typically between 5-20 amino acids in length) and a single transmembrane domain - the majority of the protein, consisting of the stem region and aminoterminal catalytic domain, is found within the
Golgi lumen. Given that glycosyltransferases and glycosidases make up the bulk of Golgi resident membrane proteins, the fact that such a small portion of these proteins is exposed to the cytoplasm is striking. Nonetheless, despite their modest length and lack of amino acid sequence similarity, the cytoplasmic regions of these enzymes are known to make a significant contribution to their retention in the Golgi.

Glycan addition is a sequential process and many glycosyltransferases occupy distinct subcompartments in the Golgi that often reflect the order in which the enzymes contribute to glycan addition. The subcompartment-specific distribution patterns shown by glycosyltransferases have made these proteins ideally suited to studies on the mechanisms of Golgi protein retention. Indeed, the picture of these mechanisms that have emerged from such studies revealed that overall; glycosyltransferases employ a variety of retention strategies. For example, the Golgi retention of some glycosyltransferases is mediated by protein-protein 
D.K. Banfield

interactions (Opat et al. 2000; Qian et al. 2001; Giraudo and Maccioni 2003; Weisz et al. 1993) whereas for others, the composition and length of the transmembrane domain (Munro 1991, 1995a,b; Aoki et al. 1992; Tang et al. 1992; Teasdale et al. 1992; Wong et al. 1992; Machamer et al. 1993; Nilsson et al. 1991; Becker et al. 2000; Sousa et al. 2003), the cytoplasmic tail (Lussier et al. 1995; Milland et al. 2001; Uliana et al. 2006; Okamoto et al. 2008), the cytoplasmic tail and transmembrane domains together (Zerfaoui et al. 2002; Fenteany and Colley 2005), or the transmembrane domain and luminal stem region together (Graham and Krasnov 1995; Nilsson et al. 1996; Grabenhorst and Conradt 1999) are crucial. Although it appears that no single mechanism or feature of a protein can account for the retention of all glycosyltransferases in the Golgi (Colley 1997; Munro, 1998; Opat et al. 2001; Saint-JoreDupas et al. 2006; Tu and Banfield 2010), for the majority of enzymes examined to date, Golgi residence can be established using the cytoplasmic tail and transmembrane domain (Czlapinski and Bertozzi 2006; Tu and Banfield 2010, and references therein).

Protein Aggregation/Kin-Recognition as a Golgi Retention Mechanism

Glycosyltransferases can be found in cells as either monomers, or homo- or hetero-oligomers (Jungmann and Munro 1998; Kojima et al. 1999; Lee et al. 2009; Chen et al. 2000; Opat et al. 2000; Giraudo and Maccioni 2003; Fenteany and Colley 2005). Such oligomerization has been shown not only to be important for Golgi retention of these proteins (Fig. 2), but also in some instances, to be important for the function of the associated glycosyltransferases (McCormick et al. 2000; Giraudo et al. 2001; de Graffenried and Bertozzi 2004). Studies on glycosyltransferase localization led to two models for Golgi resident integral membrane protein retention (Bretscher and Munro 1993; Nilsson et al. 1993a). The first, known as the kin-recognition model (Nilsson et al. 1993a, 1994), proposed that the aggregation of Golgi resident proteins, in particular glycosyltransferases, functioned to exclude these proteins from transport vesicles as they were considered to be too large; and hence this resulted in their retention in the Golgi (Nilsson et al. 1993a). Aggregationbased retention of viral membrane proteins in the Golgi had also been reported (Weisz et al. 1993) and this raised the possibility that protein-aggregation might represent a general, albeit protein-specific, Golgi protein retention mechanism. The ability of a particular glycosyltransferase to form aggregates and/or oligomerize, relies on characteristics (e.g., its length and amino acid composition) of the transmembrane domain or the transmembrane domain and luminal stem region (Weisz et al. 1993; Nilsson et al. 1996; Opat et al. 2000; Qian et al. 2001; Fenteany et al. 2005).

\section{Transmembrane Domain-Mediated Golgi Retention}

The second model for Golgi protein retention was based on the observation that alterations to the length of the transmembrane spanning region of certain glycosyltransferases affected their retention in the Golgi (Munro 1991; Bretscher and Munro 1993). Comparisons of the length and composition of Golgi integral membrane proteins with their counterparts on the cell surface revealed that the transmembrane domains of Golgi proteins were generally shorter than those of the cell surface membrane proteins (Fig. 2) (Bretscher and Munro 1993; Munro 1995a,b). This correlates with what was understood about membrane bilayer thickness in the early secretory pathway and at the cell surface, the latter being thicker. The model proposed that the transmembrane domains of Golgi membrane proteins, in particular type II proteins, prevented their entry into the sterolenriched and thicker bilayers of Golgi-derived transport vesicles destined to the cell surface (Bretscher and Munro 1993; Munro 1995a, 1998; Klemm et al. 2009). The features of Golgi membrane proteins that are thought to exclude them from transport vesicles destined to the cell surface are the length and amino acid composition of their transmembrane domains. Golgi membrane protein transmembrane domains 
are normally shorter than their plasma membrane counterparts and are typically enriched in amino acids with aromatic side chains. There is experimental support for this model: for example, the retention of some glycosyltransferases, Golgi-resident SNARE proteins, and viral proteins has been shown to be dependent on the length of their transmembrane domains (Banfield et al. 1994; Schaecher et al. 2008). In addition, transmembrane domain length can also influence the transport dynamics of membrane protein reporters (Dukhovny et al. 2009). However, it is unlikely that the length of the membrane-spanning region accounts entirely for the localization Golgi resident integral membrane proteins.

A recent study has reexamined the length and amino acid sequence compositions of integral membrane protein residents of components of the secretory pathway and plasma membrane from large datasets (Sharpe et al. 2010). This study corroborated the role of transmembrane domains as general sorting determinants for integral membrane proteins and revealed that intracellular protein localization, at least for type I and type II proteins, can be reliably predicted from the length and amino acid composition of the transmembrane domain.

How might the composition and length of Golgi membrane proteins account for their retention? Dimerization via the transmembrane has been shown to account for the retention of some proteins that exist as oligomers (Machamer et al. 1993; Souza et al. 2003), but this mode of retention cannot account for proteins that exist as monomers. The most plausible explanation would seem to involve characteristics of membranes and in particular, the lipid composition of Golgi subcompartments, as well as characteristics of amino acids enriched in Golgi resident protein transmembrane domains (Sharpe et al. 2010).

\section{Golgi Membrane Lipid Composition-Based Retention}

The transmembrane-based model for Golgi protein retention suggested that a gradient of sterols in membranes of the secretory pathway, and cholesterol in particular, might account for this mode of retention (Bretscher and Munro 1991). However, some organisms do not require cholesterol and therefore a role for sterols could not be an evolutionarily conserved feature of this mode of retention (Rolls et al. 1997). Moreover, it is not clear that differences in sterol composition within the Golgi itself could be sufficient to account for subcompartment specific transmembrane domain-based retention. In any case, the capacity of membrane protein transmembrane domains to specify Golgi subcompartment retention should presumably be reflected in the lipid composition of the organelle.

More recently, a model that also includes lipid-based protein retention has been proposed (Patterson et al. 2008). This lipid-based partitioning model posits that integral membrane proteins rapidly partition into Golgi membrane domains on the basis of the properties of individual membrane compartments (Fig. 2). The investigators proposed that differences in the ratios of lipids, in particular the ratio of glycerophospholipids to sphingolipids (which are lowest in the cis and highest in the transGolgi) could account for observed Golgi protein distributions in cells. Presumably, integral membrane proteins with different preferences for glycerophospholipid: sphingolipid ratios would be enriched Golgi subcompartments that contain the preferable lipid composition (Patterson et al. 2008; Lippincott-Schwartz and Phair 2010; Sharpe et al. 2010).

\section{Amino Acid Sequence Motif-Based Golgi Retention Mechanisms}

Amino acid sequence motifs that function as sorting signals, such as the carboxy-terminal "KKXX" and "K/HDEL" motifs, are a welldocumented means by which ER resident proteins are retrieved from the Golgi via COPIcoated vesicles (Teasdale and Jackson 1996). In contrast, there are relatively few examples of Golgi-resident proteins that are known to require an amino acid sequence-based motif for their steady-state localization. For those Golgi resident proteins that do employ such a 
D.K. Banfield

retention mechanism, it appears that steadystate localization relies on a dynamic process in which proteins are retained at steady-state via successive rounds of retrograde and anterograde transport.

\section{Golgi Retention of Glycosyltransferases by Vps74/GOLPH3}

The transmembrane domains of many Golgi resident Type II proteins appear to play a prominent role in the retention of this class of membrane protein. An alteration to the length and in some cases the composition of transmembrane domains, results in mislocalization of proteins either to the cell surface or to lysosomal-like compartments of the cell. However, several glycosyltransferases have been shown to cycle both within the Golgi, and between the Golgi and the ER by a process that requires a functional COPIcoat-deficiencies in COPI function resulted in protein mislocalization (Harris et al. 1996; Storrie et al. 1998; Todorow et al. 2000).

The most likely location of a COPI-binding site on glycosyltransferases is the cytoplasmic domain and several studies have revealed a role for this region in the Golgi retention of these proteins (Fig. 2) (Osman et al. 1996; Milland et al. 2001; Uliana et al. 2006; Saint-JoreDupas et al. 2006; Schaub et al. 2006; Okamoto et al. 2008; Christiansen et al. 2009). However, as the carboxy-terminal tails of these glycosyltransferases lacked canonical COPI-binding motifs, it was not apparent precisely how the cytoplasmically-exposed portion of these proteins mediated Golgi retention.

Although glycosyltransferases share an enzymatic domain in common, there is relatively little overall amino acid similarity among this group of proteins. As such, it was generally accepted that glycosyltransferases lacked amino acid sequence-based (signal-based) motifs and in particular, canonical COPI binding motifs that might contribute to their steady-state retention in the Golgi. However, a recent study has revealed the presence of an amino acid motif in the cytoplasmic tail of numerous yeast glycosyltransferases that is important for the retention of these enzymes in the Golgi ( $\mathrm{Tu}$ et al.
2008). This motif (F/L-L/I/V-X-X-R/K, in which $\mathrm{X}$ is any amino acid) is required for binding to an evolutionarily conserved Golgi peripheral membrane protein termed Vps74p in yeast (Fig. 2). This protein is also known as GOLPH3; GOLPH3L (Scott et al. 2009),

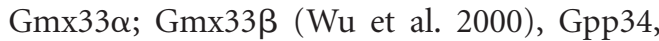
Gpp34R (Bell et al. 2001), and MIDAS (Nakashima-Kamimura et al. 2005) in other organisms and it is hereafter referred to as GOLPH3 or GOLPH3L. Vps74p in turn binds to the heptameric COPI coat complex coatomer ( Tu et al. 2008). Cells that lack Vps74p mislocalize a number of glycosyltransferases, and alterations to the Vps74 binding site on one glycosyltransferase in particular, Kre2p, was shown to be sufficient to mislocalize this protein to the vacuole in which it was subsequently degraded (Schmitz et al. 2008; Tu et al. 2008). The current view is that Vps74p/GOLPH3 acts as a late-Golgi resident glycosyltransferase sorting receptor for the COPI coat ( $\mathrm{Tu}$ et al. 2008; Tu and Banfield 2010).

GOLPH3 and Vps74p have been shown to be novel phosphatidylinositol (4) phosphate $(\mathrm{PI}(4) \mathrm{P})$-binding proteins and in the case of Vps74p, knocking down the ability of the protein to bind to $\mathrm{PI}(4) \mathrm{P}$ has been reported to reduce Golgi membrane binding and to lead to glycosyltransferase mislocalization (Dippold et al. 2009; Wood et al. 2009; Mayinger 2011). Despite the fact that the Vps74p binding consensus sequence $(\mathrm{F} / \mathrm{L}-\mathrm{L} / \mathrm{I} / \mathrm{V}-\mathrm{X}-\mathrm{X}-\mathrm{R} / \mathrm{K})$ is absent from the cytoplasmic tails of human glycosyltransferases (Giraudo and Maccioni 2003) both GOLPH3 and GOLPH3L can functionally compensate for the absence of Vps74p from yeast cells (Tu et al. 2008).

The observation that the human GOLPH3 proteins can bind to a motif that is absent from their own enzymes seems somewhat paradoxical. However, there is some, albeit indirect, evidence that GOLPH3 proteins may play a role in the retention of Golgi resident glycosyltransferases in mammalian cells. Amino acid substitutions that interfere with PI(4)P-binding, result in a loss of Vps74p-membrane association in yeast cells and in mislocalization of glycosyltransferases (Wood et al. 2009). 
While in mammalian cells reduced levels of Sac1, the major PI(4)P phosphatase, perturbs the polarized distribution of PI(4)P (which is normally restricted to the TGN) and results in the mislocalization of two medial Golgiresident glycosyltransferases (Cheong et al. 2010). The findings of Cheong et al. (2010) taken together with the observations that both Vps74p and GOLPH3 can bind to PI(4)P and that Vps74p requires its PI(4)P-binding capability for Golgi-retention of glycosyltransferases are consistent with a direct role for GOLPH3 proteins in glycosyltransferase retention, at least in mammalian cells.

Signal-Based Retention of Golgi Resident Proteins via Amino-Terminal

Arginine-Based Motifs

Arginine-based motifs (-RR-, -RXR-, and -RRR-) were initially identified as ER retrieval signals on the amino termini of type II integral membrane proteins (Schutze and Jackson 1994). However, arginine-based sorting signals have since been identified in membrane proteins of various topologies and in a variety of positions within the proteins (Michelsen et al. 2005; Uemura et al. 2009; Fig. 2). Evidence for an arginine signal-based retention mechanism in the retention of Golgi resident proteins has come from studies on Och1p and Mnn9p, two yeast glycosyltransferases that show distinct recycling repertoires. Although both Och1p and Mnn9p are predicted to contain Vps74pbinding motifs (Tu et al. 2008), they display distinct trafficking routes within the Golgi. Och1p can be retrieved from the trans-Golgi to the cis-Golgi (Harris and Waters 1996), but is not retrieved from the cis-Golgi to the ER in cells that are conditionally defective in ER export (Todorow et al. 2000). In contrast, Mnn9p cycles between the Golgi and the ER (Todorow et al. 2000; Okamoto et al. 2008). Examination of the trafficking properties of chimeras between Och1p and Mnn9p established that an arginine-based motif (-RXR-) in the cytoplasmic domain was crucial for the retrograde transport of Mnn9p and Mnn9p-Och1p chimera from the Golgi to the ER (Okamoto et al. 2008). An arginine-based motif has also been shown to be important for the dynamic ER retention of the type II membrane protein, glycosidase I (Hardt et al. 2003; Boulaflous et al. 2009).

Although it is not known whether the cytoplasmic tail of Mnn9p can bind to the COPI coat, there is mounting evidence to suggest that arginine-based motifs can mediate binding to coatomer (Michelsen et al. 2007; Sharma et al. 2010). The prospect that arginine motifs may contribute to the dynamic retention of glycosyltransferases is intriguing, particularly as the cytoplasmic domains of numerous mammalian glycosyltransferases contain such sequences (Giraudo and Maccioni 2003; Tu et al. 2008). Thus, retention of glycosyltransferases in the Golgi may involve two sorting signalbased mechanisms; one that requires Vps74p to mediate incorporation of enzymes into COPIcoated vesicles, presumably from Golgi membranes enriched in $\mathrm{PI}(4) \mathrm{P}$, whereas the other requires arginine-based motifs (Fig. 2).

\section{Signal-Based Retention of Golgi Resident Proteins via Carboxy-Terminal Lysine-Based Motifs}

The glycosylation of proteins and lipids depends on nucleotide-sugar conjugates that are translocated from the cytoplasm into the lumen of the ER or Golgi via multispanning membrane proteins called nucleotide-sugar transporters (NSTs) (Berninsone and Hirschberg 2000; Handford et al. 2006). These display ER and Golgi distributions that reflect the substrate requirements of the compartment-specific glycosyltransferases and additional enzymes that use the translocated nucleotide-sugars as substrates (Berninsone and Hirschberg 2000; Handford et al. 2006). The translocation of particular nucleotide-sugar conjugates shows a high degree of compartment specificity, with the majority of known nucleotide-sugar transporters operating on the ER or Golgi but rarely on both organelles. Presumably, the relationship between NSTs and the glycosyltransferases that depend on the nucleotide-sugars they translocate, should be intrinsically linked. 
D.K. Banfield

Despite the apparent biological importance for colocalization of NSTs and their cognate glycosyltransferases, very little is understood about the mechanism by which NSTs are localized to the Golgi. Most of what we currently understand comes from studies in yeast. In budding yeast cells, glycosylation in the Golgi only involves mannose, and yeast cells express a single and essential GDP-mannose transporter called Vrg4p (Dean et al. 1997). Vrg4p has been shown to dynamically localize to the Golgi at steady-state by virtue of a carboxy-terminal lysine rich motif, which binds to COPI and is required for retrieval of $\operatorname{Vrg} 4 \mathrm{p}$ from the Golgi (Abe et al. 2004; Fig. 2). Substitution of other amino acids for lysine, results in the redirection of the mutant protein to the vacuole (the yeast equivalent of the lysosome) (Abe et al. 2004). Thus, Vrg4p's Golgi retention relies on iterative cycles of COPI-dependent retrograde transport to the ER and forward transport, the disruption of which results in the exit of the protein from the Golgi and its delivery to the vacuole.

The arrangement of lysines in the carboxyterminal tail of Vrg4p does not conform to that of a canonical COPI-binding carboxy-terminal -KKXX motif (Cosson and Letourneur 1994), but is rather more reminiscent of sequences that have been shown to be important for the Golgi localization of the multispanning membrane protein Rer1p (Sato et al. 2001). Yeast cells also express two additional NSTs, Hutlp (a GDP-galactose NST) (Kainuma et al. 2001) and Yea4p (a presumptive Uridine diphosphate-Nacetylglucosamine (UDP-GlcNAc) NST) (Abe et al. 2004). Like Vrg4p, both Yea4p and Hutlp contain lysine residues in their carboxy-terminal tails, although the importance of these residues in the localization of these NSTs to the ER (Yealp) and Golgi (Hutlp) has not yet been explored.

Although the majority of proteins bearing arginine- and lysine-based motifs are localized to the ER at steady-state, there are a few examples of proteins that contain such motifs that are retained in the Golgi. Two such examples are the type I lectin-like proteins Emp47p and Emp46p, which contain canonical -KKXX motifs at their carboxyl termini (Schroder et al. 1995; Sato and Nakano 2002). What might account for differences in steady-state localization for proteins that bear essentially what could be considered to be functionally equivalent sorting signals? Although this has not been examined experimentally as yet, in line with the premise for Golgi protein retention emphasized here, likely explanations may include rapid export from the ER (Sato and Nakano 2002) coupled with generally slower retrieval from the Golgi brought about by protein-protein interactions and/or intrinsic Golgi-retention signals such as features of the transmembrane domain.

\section{Protein Conformational-Based Golgi Retention Mechanisms}

Soluble NSF Attachment Protein Receptors (SNAREs) are distributed throughout the endomembrane network in which they participate in the latter stages of intracellular membrane fusion events. SNARE proteins are type II integral membrane proteins that consist of a carboxy-terminal transmembrane domain and a cytoplasmic domain (Fig. 1). In contrast to the glycosyltransferases and glycosidases, the majority of the amino acid sequence of a SNARE protein $(\sim 100-350$ amino acids, depending on the SNARE) is exposed to the cytoplasm. The transmembrane domains of Golgi resident SNAREs are known to contain targeting information (Banfield et al. 1994). Despite the importance of the transmembrane domain sequence in the retention of SNAREs in the Golgi, Golgi resident SNAREs can also be mislocalized in cells deficient in the COPI coat (Ballensiefen et al. 1998; Ossipov et al. 1999). These observations suggest that Golgi resident SNAREs may be retained in part by iterative cycles of retrograde and anterograde transport, mediated by interactions between their cytoplasmic domains and the COPI and COPII coats. Indeed, it is now generally accepted that Golgi resident SNAREs cycle between the Golgi and the ER (Wooding and Pelham 1998; Cosson et al. 2005).

Although sorting signals that direct the COPII-mediated export of Golgi resident 
SNAREs from the ER have been identified (Mossessova et al. 2003), peptide motifs that direct the interactions between Golgi resident SNAREs and the COPI coat have not yet been described. Although it remains to be established whether Golgi SNAREs contain canonical or "novel" peptide motifs that direct their binding to the COPI coat, there is some biochemical evidence that suggests SNARE protein conformation may play an important role in the COPI-mediated dynamic retention of Golgi SNAREs (Rein et al. 2002; Schlinder and Spang 2007).

In in vitro mixing assays, purified yeast coatomer binds poorly to Golgi SNAREs (Rein et al. 2002). However, prior exposure of SNAREs to the Arf GTPase activating protein (GAP), Glo3p, was found to greatly enhance binding between SNAREs and coatomer. Glo3p increases the $\alpha$ helical content of SNAREs and in this way is thought to alter the structural composition of SNAREs - an important prerequisite of COPI binding in vitro (Schlinder and Spang 2007). Although the physiological relevance of these biochemical studies awaits further investigation, such a mode of sorting is not without precedent. Conformation-dependent associations between Golgi SNAREs and COPII (Mancias and Goldberg 2007), and between SNAREs and clathrin adaptors, have also been reported (Miller et al. 2007; Pryor et al. 2008). In the case of the COPII-SNARE association, alterations to the conformation of the SNARE resulted in a loss of COPII binding (Mancias and Goldberg 2007). Conformation-dependent sorting motifs may therefore represent an additional mode of steady-state Golgi protein retention.

\section{LOCALIZATION OF OTHER GOLGI RESIDENT PROTEINS}

In this review, I have focused on our current understanding of the mechanisms that cells employ to retain integral membrane proteins in the Golgi. However, numerous peripheral membrane proteins are also localized to the Golgi, either through protein-protein interactions or through the posttranslational addition of lipids (e.g., palmitoylation, prenylation, or myristoylation) combined with protein-protein interactions (Behnia et al. 2004; Fukasawa et al. 2004; Setty et al. 2004; Kamena et al. 2008; Rocks et al. 2010). Many of these peripheral membrane proteins play important roles in protein trafficking through the Golgi and in so doing, contribute both directly and indirectly to Golgi protein retention (Ungar et al. 2006; Sacher et al. 2008; Smith and Lupashin 2008; Schmitt 2010). Of particular relevance to Golgi, protein retention is the recruitment of coatomer from the cytoplasm to Golgi membranes, a process that relies on the membrane association of the N-myristoylated GTPase Arf1 (Orci et al. 1993; Palmer et al. 1993; Kahn, 2009; Liu et al. 2009). Arf1 is recruited from the cytoplasm to Golgi membranes in the GDP-bound state (Arf1-GDP) after which it is converted to Arf1-GTP via a GDP-GTP exchange factor. Arf1-GTP undergoes a conformation change, which culminates in the insertion of its $\mathrm{N}$ myristoyl group into Golgi membranes. Similarly, recruitment of GRIP domain-containing golgins-which function as vesicle tethersrelies on the successive Golgi membrane association of two Arf-like GTPases (Arls), Arl3, and Arl1 (Behnia et al. 2004; Setty et al. 2004; Behnia and Munro 2005; Gillingham and Munro 2007). Unlike Arf, Arl3 is not myristoylated but instead it is acetylated. Recruitment of acetylated Arl3 to Golgi membranes requires the multispanning membrane protein Sys1, which functions as a transmembrane protein receptor for Arl3. The successful recruitment of Arl3 facilitates the recruitment of $\mathrm{N}$-myristoylated Arl1, which in turn recruits GRIP-domain containing golgins to the Golgi (Behnia et al. 2004; Setty et al. 2004; Behnia and Munro 2005; Gillingham and Munro 2007). In contrast to Arl3, the identity of the Golgi transmembrane protein receptor for Arf remains elusive.

In addition there are, albeit few, reports of both soluble and glycosylphosphatidylinositol (GPI)-anchored protein residents of the Golgi (Lin et al. 1998; Li et al. 2007). Although Golgi protein residence appears to result largely from the physical characteristics of proteins and the lipid composition of Golgi membranes, physiological factors such as Golgi luminal $\mathrm{pH}$ 
D.K. Banfield

have also been shown to contribute to protein retention in the Golgi (Bachert et al. 2001; Rivinoja et al. 2009).

\section{CONCLUDING REMARKS}

Studies on the mechanisms by which integral membrane proteins are retained in the Golgi have revealed that protein localization at steadystate is a highly dynamic process, requiring continuous iterative rounds of Golgi-ER and ER-Golgi transport. In addition to the affinities of Golgi resident proteins for vesicle coat complexes (COPII and COPI), we now understand that the relative rates at which proteins cycle between the ER and Golgi are influenced by both Golgi resident protein-protein interactions and by Golgi protein-Golgi membrane interactions. Yet important questions remain. To what extent does Golgi membrane composition influence Golgi integral membrane protein retention and conversely to what extent does transmembrane domain composition influence membrane composition? I envision that further insight into the mechanism(s) of Golgi protein retention will come from studies examining the complex relationship between Golgi membrane lipid composition and characteristics of the transmembrane spanning sequences of Golgi resident proteins.

In addition, the recent discovery that GOLPH3 is an oncogene highlights the importance of the Golgi as a signaling hub (Scott et al. 2009; Scott and Chin, 2010). However, our understanding of the role(s) Vps74/GOLPH3 proteins play in Golgi protein retention is at an early stage. Studies aimed at understanding the relationship between GOLPH3 proteins and cell growth, signaling and Golgi protein retention, are therefore likely to yield novel and important insight.

\section{ACKNOWLEDGMENTS}

Research in my laboratory was supported by the Research Grants Council of Hong Kong (660007 and 660009). I thank Dr. Sarah Ho for comments on the manuscript.

\section{REFERENCES}

Abe M, Noda Y, Adachi H, Yoda K. 2004. Localization of GDP-mannose transporter in the golgi requires retrieval to the endoplasmic reticulum depending on its cytoplasmic tail and coatomer. J Cell Sci 117: 5687-5696.

Aoki D, Lee N, Yamaguchi N, Dubois C, Fukuda MN. 1992. Golgi retention of a trans-golgi membrane protein, galactosyltransferase, requires cysteine and histidine residues within the membrane-anchoring domain. Proc Natl Acad Sci 89: 4319-4323.

Bachert C, Lee TH, Linstedt AD. 2001. Lumenal endosomal and golgi-retrieval determinants involved in $\mathrm{pH}$-sensitive targeting of an early golgi protein. Mol Biol Cell 12: 3152-3160.

Ballensiefen W, Ossipov D, Schmitt HD. 1998. Recycling of the yeast v-SNARE Sec22p involves COPI-proteins and the ER transmembrane proteins Ufelp and Sec20p. J Cell Sci 111 (Pt 11): 1507-1520.

Banfield DK, Lewis MJ, Rabouille C, Warren G, Pelham HR. 1994. Localization of Sed5, a putative vesicle targeting molecule, to the cis-golgi network involves both its transmembrane and cytoplasmic domains. J Cell Biol 127: $357-371$.

Becker B, Haggarty A, Romero PA, Poon T, Herscovics A. 2000. The transmembrane domain of murine $\alpha$-mannosidase IB is a major determinant of golgi localization. Eur J Cell Biol 79: 986-992.

Behnia R, Munro S. 2005. Organelle identity and the signposts for membrane traffic. Nature 438: 597-604.

Behnia R, Panic B, Whyte JR, Munro S. 2004. Targeting of the arf-like GTPase Arl3p to the Golgi requires Nterminal acetylation and the membrane protein Sys1p. Nat Cell Biol 6: 405-413.

Bell AW, Ward MA, Blackstock WP, Freeman HN, Choudhary JS, Lewis AP, Chotai D, Fazel A, Gushue JN, Paiement J, et al. 2001. Proteomics characterization of abundant golgi membrane proteins. J Biol Chem 276: 5152-5165.

Berninsone PM, Hirschberg CB. 2000. Nucleotide sugar transporters of the golgi apparatus. Curr Opin Struct Biol 10: 542-547.

Bonifacino JS, Rojas R. 2006. Retrograde transport from endosomes to the trans-golgi network. Nat Rev Mol Cell Biol 7: 568-579.

Boulaflous A, Saint-Jore-Dupas C, Herranz-Gordo MC, Pagny-Salehabadi S, Plasson C, Garidou F, Kiefer-Meyer MC, Ritzenthaler C, Faye L, Gomord V. 2009. Cytosolic N-terminal arginine-based signals together with a luminal signal target a type II membrane protein to the plant ER. BMC Plant Biol 9: 144.

Bretscher MS, Munro S. 1993. Cholesterol and the golgi apparatus. Science 261: 1280-1281.

Chen C, Ma J, Lazic A, Backovic M, Colley KJ. 2000. Formation of insoluble oligomers correlates with ST6Gal I stable localization in the golgi. J Biol Chem 275: 13819-13826.

Cheong FY, Sharma V, Blagoveshchenskaya A, Oorschot VM, Brankatschk B, Klumperman J, Freeze HH, Mayinger P. 2010. Spatial regulation of golgi phosphatidylinositol-4-phosphate is required for enzyme localization and glycosylation fidelity. Traffic 11: 1180-1190. 
Christiansen D, Milland J, Dodson HC, Lazarus BD, Sandrin MS. 2009. The cytoplasmic and transmembrane domains of secretor type $\alpha 1,2$ fucosyltransferase confer atypical cellular localisation. J Mol Recognit 22: 250-254.

Colley KJ. 1997. Golgi localization of glycosyltransferases: More questions than answers. Glycobiology 7: 1-13.

Cosson P, Letourneur F. 1994. Coatomer interaction with di-lysine endoplasmic reticulum retention motifs. Science 263: 1629-1631.

Cosson P, Ravazzola M, Varlamov O, Sollner TH, Di Liberto M, Volchuk A, Rothman JE, Orci L. 2005. Dynamic transport of SNARE proteins in the golgi apparatus. Proc Natl Acad Sci 102: 14647-14652.

Czlapinski JL, Bertozzi CR. 2006. Synthetic glycobiology: Exploits in the golgi compartment. Curr Opin Chem Biol 10: 645-651.

de Graffenried CL., Bertozzi CR. 2004. The roles of enzyme localisation and complex formation in glycan assembly within the golgi apparatus. Curr Opin Cell Biol 16: 356-363.

Dean N, Zhang YB, Poster JB. 1997. The VRG4 gene is required for GDP-mannose transport into the lumen of the golgi in the yeast, saccharomyces cerevisiae. J Biol Chem 272: 31908-31914.

Dippold HC, Ng MM, Farber-Katz SE, Lee SK, Kerr ML, Peterman MC, Sim R, Wiharto PA, Galbraith KA, Madhavarapu S, et al. 2009. GOLPH3 bridges phosphatidylinositol-4- phosphate and actomyosin to stretch and shape the golgi to promote budding. Cell 139: 337-351.

Dukhovny A, Yaffe Y, Shepshelovitch J, Hirschberg K. 2009. The length of cargo-protein transmembrane segments drives secretory transport by facilitating cargo concentration in export domains. J Cell Sci 122: 1759-1767.

Fenteany FH, Colley KJ. 2005. Multiple signals are required for $\alpha 2,6$-sialyltransferase (ST6Gal I) oligomerization and golgi localization. J Biol Chem 280: 5423-5429.

Fukasawa M, Varlamov O, Eng WS, Sollner TH, Rothman JE. 2004. Localization and activity of the SNARE Ykt6 determined by its regulatory domain and palmitoylation. Proc Natl Acad Sci 101: 4815-4820.

Gill DJ, Chia J, Senewiratne J, Bard F. 2010. Regulation of Oglycosylation through golgi-to-ER relocation of initiation enzymes. J Cell Biol 189: 843-858.

Gillingham AK, Munro S. 2007. The small G proteins of the arf family and their regulators. Annual Rev Cell Dev Biol 23: 579-611.

Giraudo CG, Maccioni HJ. 2003. Ganglioside glycosyltransferases organize in distinct multienzyme complexes in CHO-K1 cells. J Biol Chem 278: 40262-40271.

Giraudo CG, Daniotti JL, Maccioni HJ. 2001. Physical and functional association of glycolipid N-acetyl-galactosaminyl and galactosyl transferases in the golgi apparatus. Proc Natl Acad Sci 98: 1625-1630.

Gleeson PA. 1998. Targeting of proteins to the golgi apparatus. Histochem Cell Biol 109: 517-532.

Glick BS, Nakano A. 2009. Membrane traffic within the golgi apparatus. Annu Rev Cell Dev Biol 25: 113-132.

Grabenhorst E, Conradt HS. 1999. The cytoplasmic, transmembrane, and stem regions of glycosyltransferases specify their in vivo functional sublocalization and stability in the golgi. J Biol Chem 274: 36107-36116.

Graham TR, Krasnov VA. 1995. Sorting of yeast $\alpha 1,3$ mannosyltransferase is mediated by a lumenal domain interaction, and a transmembrane domain signal that can confer clathrin-dependent golgi localization to a secreted protein. Mol Biol Cell 6: 809-824.

Handford M, Rodriguez-Furlan C, Orellana A. 2006. Nucleotide-sugar transporters: Structure, function and roles in vivo. Braz J Med Biol Res 39: 1149-1158.

Hardt B, Kalz-Fuller B, Aparicio R, Volker C, Bause E. 2003. (Arg) 3 within the $\mathrm{N}$-terminal domain of glucosidase I contains ER targeting information but is not required absolutely for ER localization. Glycobiology 13: 159-168.

Harris SL, Waters MG. 1996. Localization of a yeast early golgi mannosyltransferase, Ochlp, involves retrograde transport. J Cell Biol 132: 985-998.

Heinrich R, Rapoport TA. 2005. Generation of nonidentical compartments in vesicular transport systems. J Cell Biol 168: $271-280$.

Jackson CL. 2009. Mechanisms of transport through the golgi complex. J Cell Sci 122: 443-452.

Jungmann J, Munro S. 1998. Multi-protein complexes in the cis-golgi of saccharomyces cerevisiae with $\alpha$-1,6-mannosyltransferase activity. EMBO J 17: 423-434.

Kahn RA. 2009. Toward a model for arf GTPases as regulators of traffic at the golgi. FEBS Lett 583: 3872-3879.

Kainuma M, Chiba Y, Takeuchi M, Jigami Y. 2001. Overexpression of HUT1 gene stimulates in vivo galactosylation by enhancing UDP-galactose transport activity in saccharomyces cerevisiae. Yeast 18: 533-541.

Kamena F, Diefenbacher M, Kilchert C, Schwarz H, Spang A. 2008. Yptlp is essential for retrograde golgi-ER transport and for golgi maintenance in S. cerevisiae. J Cell Sci 121: 1293-1302.

Klemm RW, Ejsing CS, Surma MA, Kaiser HJ, Gerl MJ, Sampaio JL, de Robillard Q, Ferguson C, Proszynski TJ, Shevchenko A, et al. 2009. Segregation of sphingolipids and sterols during formation of secretory vesicles at the transgolgi network. J Cell Biol 185: 601-612.

Kojima H, Hashimoto H, Yoda K. 1999. Interaction among the subunits of golgi membrane mannosyltransferase complexes of the yeast saccharomyces cerevisiae. Biosci Biotechnol Biochem 63: 1970-1976.

Lee PL, Kohler JJ, Pfeffer SR. 2009. Association of $\beta$-1,3-N-acetylglucosaminyltransferase 1 and $\beta$-1,4-galactosyltransferase 1, trans-golgi enzymes involved in coupled poly-N-acetyllactosamine synthesis. Glycobiology 19: 655-664.

Li X, Kaloyanova D, van Eijk M, Eerland R, van der Goot G, Oorschot V, Klumperman J, Lottspeich F, Starkuviene V, Wieland FT, et al. 2007. Involvement of a golgi-resident GPI-anchored protein in maintenance of the golgi structure. Mol Biol Cell 18: 1261-1271.

Lin P, Le-Niculescu H, Hofmeister R, McCaffery JM, Jin M, Hennemann H, McQuistan T, De Vries L, Farquhar MG. 1998. The mammalian calcium-binding protein, nucleobindin (CALNUC), is a golgi resident protein. J Cell Biol 141: $1515-1527$. 
D.K. Banfield

Lippincott-Schwartz J, Phair RD. 2010. Lipids and cholesterol as regulators of traffic in the endomembrane system. Annu Rev Biophys 39: 559-578.

Liu Y, Kahn RA, Prestegard JH. 2009. Structure and membrane interaction of myristoylated ARF1. Structure 17: 79-87.

Lussier M, Sdicu AM, Ketela T, Bussey H. 1995. Localization and targeting of the saccharomyces cerevisiae Kre2p/ Mntlp $\alpha$ 1,2-mannosyltransferase to a medial-golgi compartment. J Cell Biol 131: 913-927.

Machamer CE. 1991. Golgi retention signals: Do membranes hold the key? Trends Cell Biol 1: 141-144.

Machamer CE, Grim MG, Esquela A, Chung SW, Rolls M, Ryan K, Swift AM. 1993. Retention of a cis-golgi protein requires polar residues on one face of a predicted $\alpha$-helix in the transmembrane domain. Mol Biol Cell 4: 695-704.

Mancias JD, Goldberg J. 2007. The transport signal on Sec22 for packaging into COPII-coated vesicles is a conformational epitope. Mol Cell 26: 403-414.

Mayinger P. 2011. Signaling at the Golgi. Cold Spring Harb Perspect Biol doi:10.1101/cshperspect.a005314.

McCormick C, Duncan G, Goutsos KT, Tufaro F. 2000. The putative tumor suppressors EXT1 and EXT2 form a stable complex that accumulates in the golgi apparatus and catalyzes the synthesis of heparan sulfate. Proc Natl Acad Sci 97: 668-673.

Michelsen K, Schmid V, Metz J, Heusser K, Liebel U, Schwede T, Spang A, Schwappach B. 2007. Novel cargobinding site in the $\{\beta\}$ and $\{\delta\}$ subunits of coatomer. J Cell Biol 179: 209-17.

Michelsen K, Yuan H, Schwappach B. 2005. Hide and run. Arginine-based endoplasmic-reticulum-sorting motifs in the assembly of heteromultimeric membrane proteins. EMBO Rep 6: 717-722.

Milland J, Taylor SG, Dodson HC, McKenzie IF, Sandrin MS. 2001. The cytoplasmic tail of $\alpha$ 1,2-fucosyltransferase contains a sequence for golgi localization. J Biol Chem 276: 12012-12018.

Miller SE, Collins BM, McCoy AJ, Robinson MS, Owen DJ. 2007. A SNARE-adaptor interaction is a new mode of cargo recognition in clathrin-coated vesicles. Nature 450: $570-574$.

Mossessova E, Bickford LC, Goldberg J. 2003. SNARE selectivity of the COPII coat. Cell 114: 483-495.

Munro S. 1991. Sequences within and adjacent to the transmembrane segment of $\alpha-2,6$-sialyltransferase specify golgi retention. EMBO J 10: 3577-3588.

Munro S. 1995a. A comparison of the transmembrane domains of golgi and plasma membrane proteins. Biochem Soc Trans 23: 527-530.

Munro S. 1995b. An investigation of the role of transmembrane domains in golgi protein retention. EMBO J 14: 4695-4704.

Munro S. 1998. Localization of proteins to the golgi apparatus. Trends Cell Biol 8: 11-15.

Nakashima-Kamimura N, Asoh S, Ishibashi Y, Mukai Y, Shidara Y, Oda H, Munakata K, Goto Y, Ohta S. 2005. MIDAS/GPP34, a nuclear gene product, regulates total mitochondrial mass in response to mitochondrial dysfunction. J Cell Sci 118: 5357-5367.
Nilsson T, Lucocq JM, Mackay D, Warren G. 1991. The membrane spanning domain of $\beta$-1,4-galactosyltransferase specifies trans-golgi localization. EMBO J 10: $3567-$ 3575.

Nilsson T, Slusarewicz P, Hoe MH, Warren G. 1993a. Kin recognition. A model for the retention of golgi enzymes. FEBS Lett 330: 1-4.

Nilsson T, Rabouille C, Hui N, Watson R, Warren G. 1996. The role of the membrane-spanning domain and stalk region of $\mathrm{N}$-acetylglucosaminyltransferase I in retention, kin recognition and structural maintenance of the golgi apparatus in HeLa cells. J Cell Sci 109 (Pt 7): 1975-1989.

Nilsson T, Pypaert M, Hoe MH, Slusarewicz P, Berger EG, Warren G. 1993b. Overlapping distribution of two glycosyltransferases in the golgi apparatus of HeLa cells. J Cell Biol 120: 5-13.

Nilsson T, Hoe MH, Slusarewicz P, Rabouille C, Watson R, Hunte F, Watzele G, Berger EG, Warren G. 1994. Kin recognition between medial golgi enzymes in HeLa cells. EMBO J 13: 562-574.

Okamoto M, Yoko-o T, Miyakawa T, Jigami Y. 2008. The cytoplasmic region of $\alpha-1,6$-mannosyltransferase Mnn9p is crucial for retrograde transport from the golgi apparatus to the endoplasmic reticulum in saccharomyces cerevisiae. Eukaryot Cell 7: 310-318.

Opat AS, Houghton F, Gleeson PA. 2000. Medial golgi but not late golgi glycosyltransferases exist as high molecular weight complexes. Role of luminal domain in complex formation and localization. J Biol Chem 275: 1183611845.

Opat AS, van Vliet C, Gleeson PA. 2001. Trafficking and localisation of resident golgi glycosylation enzymes. Biochimie 83: 763-773.

Orci L, Palmer DJ, Ravazzola M, Perrelet A, Amherdt M, Rothman JE. 1993. Budding from golgi membranes requires the coatomer complex of non-clathrin coat proteins. Nature 362: 648-652.

Osman N, McKenzie IF, Mouhtouris E, Sandrin MS. 1996. Switching amino-terminal cytoplasmic domains of $\alpha(1,2)$ fucosyltransferase and $\alpha(1,3)$ galactosyltransferase alters the expression of $\mathrm{H}$ substance and gal $\alpha(1,3)$ gal. J Biol Chem 271: 33105-33109.

Ossipov D, Schroder-Kohne S, Schmitt HD. 1999. Yeast ER-golgi v-SNAREs Boslp and Betlp differ in steadystate localization and targeting. J Cell Sci 112 (Pt 22): $4135-4142$.

Palmer DJ, Helms JB, Beckers CJ, Orci L, Rothman JE. 1993. Binding of coatomer to golgi membranes requires ADP-ribosylation factor. J Biol Chem 268: 12083-12089.

Patterson GH, Hirschberg K, Polishchuk RS, Gerlich D, Phair RD, Lippincott-Schwartz J. 2008. Transport through the golgi apparatus by rapid partitioning within a two-phase membrane system. Cell 133: 1055-1067.

Pfeffer SR. 2009. Multiple routes of protein transport from endosomes to the trans-golgi network. FEBS Lett 583: 3811-3816.

Pryor PR, Jackson L, Gray SR, Edeling MA, Thompson A, Sanderson CM, Evans PR, Owen DJ, Luzio JP. 2008. Molecular basis for the sorting of the SNARE VAMP7 into endocytic clathrin-coated vesicles by the ArfGAP hrb. Cell 134: 817-827. 
Qian R, Chen C, Colley KJ. 2001. Location and mechanism of $\alpha$ 2,6-sialyltransferase dimer formation. Role of cysteine residues in enzyme dimerization, localization, activity, and processing. J Biol Chem 276: 28641-28649.

Rein U, Andag U, Duden R, Schmitt HD, Spang A. 2002 ARF-GAP-mediated interaction between the ER-golg v-SNAREs and the COPI coat. J Cell Biol 157: 395-404.

Rivinoja A, Hassinen A, Kokkonen N, Kauppila A, Kellokumpu S. 2009. Elevated golgi $\mathrm{pH}$ impairs terminal $\mathrm{N}$-glycosylation by inducing mislocalization of golgi glycosyltransferases. J Cell Physiol 220: 144-154.

Rocks O, Gerauer M, Vartak N, Koch S, Huang ZP, Pechlivanis M, Kuhlmann J, Brunsveld L, Chandra A, Ellinger B, et al. 2010. The palmitoylation machinery is a spatially organizing system for peripheral membrane proteins. Cell 141: 458-471.

Rolls MM, Marquardt MT, Kielian M, Machamer CE. 1997. Cholesterol-independent targeting of golgi membrane proteins in insect cells. Mol Biol Cell 8: 2111-2118.

Sacher M, Kim YG, Lavie A, Oh BH, Segev N. 2008. The TRAPP complex: Insights into its architecture and function. Traffic 9: 2032-2042.

Saint-Jore-Dupas C, Gomord V, Paris N. 2004. Protein localization in the plant golgi apparatus and the transgolgi network. Cell Mol Life Sci 61: 159-171.

Saint-Jore-Dupas C, Nebenfuhr A, Boulaflous A, FolletGueye ML, Plasson C, Hawes C, Driouich A, Faye L, Gomord V. 2006. Plant N-glycan processing enzymes employ different targeting mechanisms for their spatial arrangement along the secretory pathway. Plant Cell 18: 3182-3200.

Sato K, Nakano A. 2002. Emp47p and its close homo$\log$ Emp46p have a tyrosine-containing endoplasmic reticulum exit signal and function in glycoprotein secretion in saccharomyces cerevisiae. Mol Biol Cell 13: 2518-2532.

Sato K, Sato M, Nakano A. 2001. Rerlp, a retrieval receptor for endoplasmic reticulum membrane proteins, is dynamically localized to the golgi apparatus by coatomer. J Cell Biol 152: 935-944.

Schaecher SR, Diamond MS, Pekosz A. 2008. The transmembrane domain of the severe acute respiratory syndrome coronavirus ORF7b protein is necessary and sufficient for its retention in the golgi complex. J Virol 82: 9477-9491.

Schaub BE, Berger B, Berger EG, Rohrer J. 2006. Transition of galactosyltransferase 1 from trans-golgi cisterna to the trans-golgi network is signal mediated. Mol Biol Cell 17: 5153-5162.

Schindler C, Spang A. 2007. Interaction of SNAREs with ArfGAPs precedes recruitment of Sec18p/NSF. Mol Biol Cell 18: 2852-2863.

Schmitt HD. 2010. Dsl1p/Zw10: Common mechanisms behind tethering vesicles and microtubules. Trends Cell Biol 20: 257-268.

Schmitz KR, Liu J, Li S, Setty TG, Wood CS, Burd CG, Ferguson KM. 2008. Golgi localization of glycosyltransferases requires a Vps74p oligomer. Dev Cell 14: 523-534.

Schroder S, Schimmoller F, Singer-Kruger B, Riezman H 1995. The golgi-localization of yeast Emp47p depends on its di-lysine motif but is not affected by the ret1-1 mutation in $\alpha$-COP. J Cell Biol 131: 895-912.

Schutze MP, Peterson PA, Jackson MR. 1994. An N-terminal double-arginine motif maintains type II membrane proteins in the endoplasmic reticulum. $E M B O J$ 13: 1696-1705.

Scott KL, Chin L. 2010. Signaling from the golgi: Mechanisms and models for golgi phosphoprotein 3-mediated oncogenesis. Clin Cancer Res 16: 2229-2234.

Scott KL, Kabbarah O, Liang MC, Ivanova E, Anagnostou V, Wu J, Dhakal S, Wu M, Chen S, Feinberg T, et al. 2009. GOLPH3 modulates mTOR signalling and rapamycin sensitivity in cancer. Nature 459: 1085-1090.

Setty SR, Strochlic TI, Tong AH, Boone C, Burd CG. 2004. Golgi targeting of ARF-like GTPase Arl3p requires its n $\alpha$-acetylation and the integral membrane protein Sys1p. Nat Cell Biol 6: 414-419.

Sharma P, Ignatchenko V, Grace K, Ursprung C, Kislinger T, Gramolini AO. 2010. Endoplasmic reticulum protein targeting of phospholamban: A common role for an Nterminal di-arginine motif in ER retention? PLoS One 5: e11496.

Sharpe HJ, Stevens TJ, Munro S. 2010. A comprehensive comparison of transmembrane domains reveals organelle-specific properties. Cell 142: 158-169.

Smith RD, Lupashin VV. 2008. Role of the conserved oligomeric golgi (COG) complex in protein glycosylation. Carbohydr Res 343: 2024-2031.

Sousa VL, Brito C, Costa T, Lanoix J, Nilsson T, Costa J. 2003. Importance of cys, gln, and tyr from the transmembrane domain of human $\alpha 3 / 4$ fucosyltransferase III for its localization and sorting in the golgi of baby hamster kidney cells. J Biol Chem 278: 7624-7629.

Storrie B, White J, Rottger S, Stelzer EH, Suganuma T, Nilsson T. 1998. Recycling of golgi-resident glycosyltransferases through the ER reveals a novel pathway and provides an explanation for nocodazole-induced golgi scattering. J Cell Biol 143: 1505-1521.

Tang BL, Wong SH, Low SH, Hong W. 1992. The transmembrane domain of $\mathrm{N}$-glucosaminyltransferase I contains a golgi retention signal. J Biol Chem 267: $10122-$ 10126.

Teasdale RD, Jackson MR. 1996. Signal-mediated sorting of membrane proteins between the endoplasmic reticulum and the golgi apparatus. Annu Rev Cell Dev Biol 12: $27-54$.

Teasdale RD, D’Agostaro G, Gleeson PA. 1992. The signal for golgi retention of bovine $\beta$ 1,4-galactosyltransferase is in the transmembrane domain. J Biol Chem 267: 13113.

Todorow Z, Spang A, Carmack E, Yates J, Schekman R. 2000. Active recycling of yeast golgi mannosyltransferase complexes through the endoplasmic reticulum. Proc Natl Acad Sci 97: 13643-13648.

Tu L, Banfield DK. 2010. Localization of golgi-resident glycosyltransferases. Cell Mol Life Sci 67: 29-41.

Tu L, Tai WC, Chen L, Banfield DK. 2008. Signal-mediated dynamic retention of glycosyltransferases in the golgi. Science 321: 404-407.

Uemura S, Yoshida S, Shishido F, Inokuchi J. 2009. The cytoplasmic tail of GM3 synthase defines its subcellular 
D.K. Banfield

localization, stability, and in vivo activity. Mol Biol Cell 20: $3088-3100$.

Uliana AS, Giraudo CG, Maccioni HJ. 2006. Cytoplasmic tails of SialT2 and GalNAcT impose their respective proximal and distal golgi localization. Traffic 7: 604-612.

Ungar D, Oka T, Krieger M, Hughson FM. 2006. Retrograde transport on the COG railway. Trends Cell Biol 16: $113-120$.

Weisz OA, Swift AM, Machamer CE. 1993. Oligomerization of a membrane protein correlates with its retention in the golgi complex. J Cell Biol 122: 1185-1196.

Wong SH, Low SH, Hong W. 1992. The 17-residue transmembrane domain of $\beta$-galactoside $\alpha$ 2,6-sialyltransferase is sufficient for golgi retention. J Cell Biol 117: $245-258$.
Wood CS, Schmitz KR, Bessman NJ, Setty TG, Ferguson KM, Burd CG. 2009. PtdIns4P recognition by Vps74/ GOLPH3 links PtdIns 4-kinase signaling to retrograde golgi trafficking. J Cell Biol 187: 967-975.

Wooding S, Pelham HR. 1998. The dynamics of golgi protein traffic visualized in living yeast cells. Mol Biol Cell 9: 2667-2680.

Wu CC, Taylor RS, Lane DR, Ladinsky MS, Weisz JA, Howell KE. 2000. GMx33: A novel family of trans-golgi proteins identified by proteomics. Traffic 1: 963-975.

Zerfaoui M, Fukuda M, Langlet C, Mathieu S, Suzuki M, Lombardo D, El-Battari A. 2002. The cytosolic and transmembrane domains of the $\beta$ 1,6 N-acetylglucosaminyltransferase (C2GnT) function as a cis to medial Golgi-targeting determinant. Glycobiology 12: 15-24. 


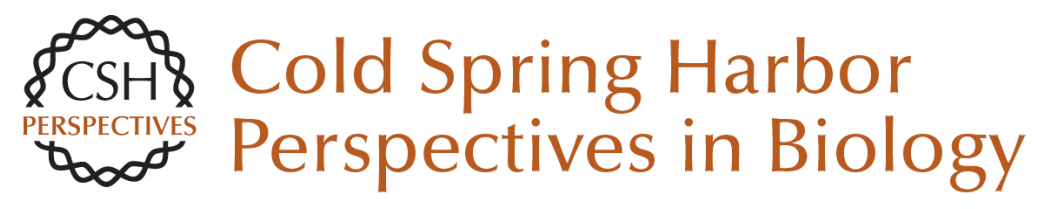

\section{Mechanisms of Protein Retention in the Golgi}

David K. Banfield

Cold Spring Harb Perspect Biol 2011; doi: 10.1101/cshperspect.a005264 originally published online April 27,2011

\section{Subject Collection The Golgi}

Structure of Golgi Transport Proteins

Daniel Kümmel and Karin M. Reinisch

\section{Golgi Biogenesis}

Yanzhuang Wang and Joachim Seemann

Golgi Glycosylation and Human Inherited

Diseases

Hudson H. Freeze and Bobby G. Ng

Models for Golgi Traffic: A Critical Assessment Benjamin S. Glick and Alberto Luini

\section{Architecture of the Mammalian Golgi} Judith Klumperman

Evolution and Diversity of the Golgi Mary J. Klute, Paul Melançon and Joel B. Dacks

Evolutionary Forces Shaping the Golgi

Glycosylation Machinery: Why Cell Surface

Glycans Are Universal to Living Cells Ajit Varki

Golgi Positioning

Smita Yadav and Adam D. Linstedt
Golgi and Related Vesicle Proteomics: Simplify to Identify Joan Gannon, John J.M. Bergeron and Tommy Nilsson

Organization of SNAREs within the Golgi Stack Jörg Malsam and Thomas H. Söllner

Golgi during Development Weimin Zhong

Entry and Exit Mechanisms at the cis-Face of the Golgi Complex Andrés Lorente-Rodríguez and Charles Barlowe

COPI Budding within the Golgi Stack Vincent Popoff, Frank Adolf, Britta Brügger, et al.

Mechanisms of Protein Retention in the Golgi David K. Banfield

The Golgin Coiled-Coil Proteins of the Golgi

Apparatus Sean Munro

Signaling at the Golgi Peter Mayinger

For additional articles in this collection, see http://cshperspectives.cshlp.org/cgi/collection/

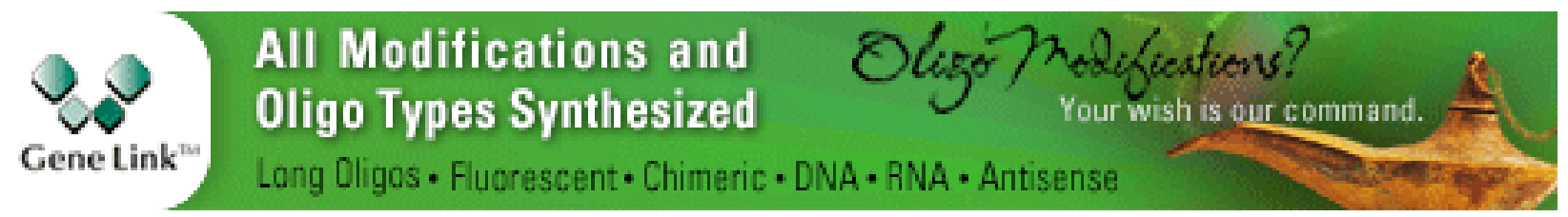

Copyright @ 2011 Cold Spring Harbor Laboratory Press; all rights reserved 